\title{
The role of transformative leadership, ICT-infrastructure and learning climate in teachers' use of digital learning materials during their classes
}

Citation for published version (APA):

Vermeulen, M., Kreijns, K., van Buuren, H., \& Van Acker, F. (2017). The role of transformative leadership, ICTinfrastructure and learning climate in teachers' use of digital learning materials during their classes. British Journal of Educational Technology, 48(6), 1427-1440. https://doi.org/10.1111/bjet.12478

DOI:

10.1111/bjet.12478

Document status and date:

Published: 01/11/2017

Document Version:

Peer reviewed version

\section{Document license:}

CC BY-NC-ND

\section{Please check the document version of this publication:}

- A submitted manuscript is the version of the article upon submission and before peer-review. There can be important differences between the submitted version and the official published version of record. People interested in the research are advised to contact the author for the final version of the publication, or visit the DOI to the publisher's website.

- The final author version and the galley proof are versions of the publication after peer review.

- The final published version features the final layout of the paper including the volume, issue and page numbers.

Link to publication

\section{General rights}

Copyright and moral rights for the publications made accessible in the public portal are retained by the authors and/or other copyright owners and it is a condition of accessing publications that users recognise and abide by the legal requirements associated with these rights.

- Users may download and print one copy of any publication from the public portal for the purpose of private study or research.

- You may not further distribute the material or use it for any profit-making activity or commercial gain

- You may freely distribute the URL identifying the publication in the public portal.

If the publication is distributed under the terms of Article $25 \mathrm{fa}$ of the Dutch Copyright Act, indicated by the "Taverne" license above, please follow below link for the End User Agreement:

https://www.ou.nl/taverne-agreement

Take down policy

If you believe that this document breaches copyright please contact us at:

pure-support@ou.nl

providing details and we will investigate your claim.

Downloaded from https://research.ou.nl/ on date: 26 Apr. 2023 
The role of transformative leadership, ICT-infrastructure and learning climate in teachers' use of digital learning materials during their classes.

Marjan Vermeulen ${ }^{1,2}$, Karel Kreijns ${ }^{2}$, Hans van Buuren ${ }^{3}$, Frederik Van Acker ${ }^{4}$

\author{
${ }^{1}$ KPC Group Netherlands \\ ${ }^{2}$ Welten Institute, Open University of the \\ Netherlands \\ ${ }^{3}$ Faculty of Psychology, Open University of the \\ Nederland \\ ${ }^{4}$ Departement of Health and Social Care, Artesis \\ Plantijn (AP) University College, Antwerpen, \\ Belgium
}

\title{
Corresponding author:
}

Marjan Vermeulen, Welten Institute, Open University of the Netherlands, Valkenburgerweg 177, 6419AT

Heerlen, the Netherlands

Email: marjan.vermeulen@ou.nl 


\section{Abstract}

This study investigated whether the school organizational variables transformative leadership (TL), ICT-infrastructure (technical and social), and organizational learning climate were related to teachers' dispositional variables attitude, perceived norm, and perceived behavior control (PBC). The direct and indirect influences of these variables on teachers' intention and use of modern technology such as digital learning materials (DLMs) were also investigated. A longitudinal design was used with three measurements spread out over three years, with 544 randomly selected teachers from the Dutch primary, secondary and vocational education. Model fit was tested using structural equation modeling (SEM).

All dispositional variables predicted the use of DLMs, mediated by teachers' intention. TL had direct and indirect relationships via ICT-infrastructure and learning climate with attitude, perceived norm, and PBC. The longitudinal design proved the chronological effect of TL on learning climate and the dispositional variables. However, not all TL dimensions had relationships with ICT-infrastructure (only TL-vision and TL-intellectual stimulation) and with learning climate (only TL-intellectual stimulation).

For educational practice, the results indicated that leadership can promote teachers' use of DLMs directly and by supporting a school wide learning climate under the condition that an ICT-infrastructure exists.

\section{What is already known about this topic}

\section{What is already known}

- Affecting teacher behavior with regard to educational practices is a complex process.

- Transformational leadership characteristics are related to teachers' innovative behavior, continuous professional development (CPD) and ICT integration in class. 
- Dispositional variables (attitude, perceived behavior control, subjective norm) mediate between distal factors and the (intended) behavior of teachers.

\section{What this paper adds}

- Insights into the relationships over three years between school (leader) characteristics, teachers' dispositional variables and teachers (intention to) use digital learning materials in their classroom.

- The important role of learning climate within the school, mediating between school leader characteristics and teachers' dispositional variables.

- Teachers' behavior regarding the use of digital learning materials is not directly affected, but follows a chain of mediating variables.

\section{Implications for practice and/or policy}

- School leaders can enhance teachers' integration of digital learning materials in class by facilitating a sound ICT-infrastructure (policy, social and technical) and by creating a positive learning climate.

- School leaders can enhance the use of digital learning materials in class by stimulating the intellectual development of teachers.

- Enhancing teachers' use of digital learning materials needs a chain of different stimuli.

Keywords: digital learning materials; transformational leadership; Integrative Model of Behavior Prediction; ICT-infrastructure; learning climate. 
Discussions about the future quality of education are conducted both nationally as well as internationally and continue to be relevant (OECD, 2014). Active learning, critical thinking, collaborative investigations, media literacy, and self-directed learning are necessary new competences (Voogt, Knezek, Cox, Knezek, \& ten Brummelhuis, 2013). ICT is an important tool for students to acquire such competences, but ICT has not yet been integrated in all schools and, therefore, is still not part of everyday teaching routines (Vrasidas, 2015).

Because the use of new technologies such as digital learning materials (DLMs) is not simply a matter of course, various incentives are necessary (Voogt, et al., 2013). From this perspective, the Dutch Ministry of Education, Culture and Science has funded a four years program (known as Wikiwijs) to encourage the use, creation and sharing of DLMs by teachers. Research has accompanied the program for four years. Based on the yearly gathered data more answers can be given on what factors predict teachers use of DLMs.

\section{The Integrated Model for Behavior Prediction and teachers' use of DLMs}

Research on human behavior has proven that context factors (e.g., leadership, culture, facilities) and individual factors (e.g. motivation) influence human behavior (Leithwood, Jantzi, \& Mascall, 2002) and specifically teachers' ICT use (Law \& Chow, 2008; Chen, 2011). The Integrated Model for Behavior Prediction (IMBP; see Fishbein \& Ajzen, 2010) focusses on how context and individual variables influence human behavior. IMBP seems to be an appropriate model to explain/predict teachers' use of DLMs (Tearle, 2003; Chen, 2011; Van Acker, Kreijns, van Buuren, \& Vermeulen, 2013).

In IMBP, three individual variables are distinguished (attitude, perceived norm and perceived behavioral control (PBC)). They are labeled as dispositional or as proximal variables because of their 'short distance' to behavior, and are direct predictors of intention. Intention, in IMBP is a predictor of behavior. The distal variables have a 'long distance' to the 
behavior and are important because they may affect one or more proximal variables. In the recent years the empirical evidence for the applicability of the IMBP in education is growing (Van Acker, et al., 2013; Chen, 2011). Tearle (2003) concluded, based on a case study design, that ICT integration in class cannot simply be explained by a list of variables, but that a framework or model is needed to allow teacher characteristics combined with organizational characteristics such as strong leadership and a learning culture. This current study proceeds our earlier findings using the IMBP as a model for the integration of ICT (Van Acker, et al., 2013; Kreijns, et al., 2013). In previous studies, teachers' intention to use DLMs has been explained using dispositional variables and organizational variables such as ICT policy and transformational leadership (TL). More detailed descriptions on the testing of IMBP has been published (see for instance Vermeulen et al., 2014, Kreijns, et al., 2013).

This current study differs in two important ways from earlier studies. First, the variables ICT-infrastructure and learning climate have not been tested before; it was hypothesized that they were mediating the relationship between TL and teachers' usage of DLMs (Tearle 2003). Second, and more important, this study was based on three data gathering points in time, spread over the last three years of the Wikiwijs project (see Table 3). Variables with the most distant from the behavior were measured first (TL and ICTinfrastructure), learning climate was measured a year later, and the dispositional variables and actual behavior two years later. Because the design of all the earlier studies were crosssectional (all data gathering happened at the same point in time), these studies were not well suited to prove non-reciprocal relations. Thus, using a longitudinal research design with three measurements in time, this article focuses on the effect of variables at the school level on teachers' use of DLMs. The central question is: "To what extent does TL, ICT-infrastructure, and organizational learning climate explain, mediated by dispositional variables attitude, perceived norm, and PBC, teachers' use of DLMs?". 


\section{School organizational variables and teachers use of DLMs}

Results from various research (e.g., Thoonen, Sleegers, Oort, Peetsma, \& Geijsel, 2011; Vanderlinde, van Braak, \& Dexter, 2012; Tondeur, Valcke, \& van Braak, 2008) have provided evidence that school organizational variables are related to teachers' behavior. However, not much research has been conducted based on models of behavioral change such as the IMBP.

Transformational leadership (TL). TL is an essential factor in sustainable innovation and it has been studied before in relation to the behavior of teachers (Thoonen, et al., 2011). TL is also related to the integration of ICT (Weng, \& Tang, 2014). TL focusses on a set of leadership behavior increasing employee motivation and performance (Leithwood \& Jantzi, 2006). Burns (1978) formulated TL as a process where "leaders and followers help each other to advance to a higher level of morale and motivation". Although many dimensions of TL have been identified (Sun \& Leithwood, 2012, Weng, \& Tang, 2014), three dimensions were most often mentioned: TL-vision, TL-individual consideration, and TL-intellectual stimulation (Geijsel, Sleegers, Stoel, \& Krüger, 2009).

Transformational leaders articulate a vision and mission related to their own values. By communicating such visions, employees give meaning to their action and develop a more collective frame of reference. For example, by communicating a clear vision on the use of DLMs, leaders can develop teachers' mindset on the usefulness and necessity of DLMs (Vanderlinde, Dexter, \& van Braak, 2012). Individual consideration relates to the provision of a supportive environment that enables learning, whereas intellectual stimulation relates to the encouragement of developing creative and innovative ideas, reframing problems as well as thinking of new ways of looking at old situations (Deinert, Homan, Boer, Voelpel, \& Guterman, 2015). Indeed, Razzak (2015) mentioned leadership that should support monthly 
meetings to exchange ideas and ICT related experiences, give feedback on ICT implementations through regular classroom visits, and setup an adequate ICT-infrastructure.

Self-efficacy (i.e., PBC; see Fishbein \& Ajzen, 2010) and attitudes proved to be important factors (Kim, Kim, Lee, Spector, \& DeMeester, 2013 ), as well as social pressure (i.e., perceived norm) (Carmeli \& Schaubroeck, 2007) in developing innovative behavior. ICT-infrastructure. For implementing DLMs in daily practice an ICT-infrastructure should be available (Wastiau, Blamire, Kearney, Quittre, Van de Gear, \& Monseur, 2013). According to Tondeur, Devos, Houtte, van Braak, \& Valcke (2009), an ICT-infrastructure refers to more components than the technical structure (PC, internet connection and the availability of educative programs) alone; it comprises ICT policy, ICT vision, and sufficient degree of competence by colleagues to use ICT. School leaders played an important role in the quality of the ICT policy (Vanderlinde et al., 2012). School leadership is related to developing and implementing policies (Scheuermann \& Pedr, 2010). The scale developed by Tondeur et al. (2008) was used to measure ICT-infrastructure.

Learning climate. Learning climate can be considered part of an organizational climate. Organizational climate is one of the concepts on which scholars have little consensus on how the concept should be defined (Thumin \& Thumin, 2011). There has been a broad and ongoing discussion how the concepts of organizational culture and climate are related. Thumin and Thumin (2011) doubted the relevance of the discussion in the light of the usefulness for measuring organizational processes. We followed their reasoning, because the focus of our study was about variables that enhance teachers' use of DLMs. How the variable is named and in what research tradition it is nested, was of less relevancy. Thus, organizational climate was defined as one's personal perceptions of the working environment (Chen, 2011). Organizational climate can be focused on specific features, for instance, on giving rewards, or — as in our case — on learning (Schneider, 2000). Learning climate was 
operationalized as a part of organizational climate and referred to one's perceptions of work settings that help or hinder learning at work (Hetland, Skogstad, Hetland, \& Mikkelsen, 2011). There is a growing body of knowledge that suggests aspects of the organizational learning climate to be related to employee learning and innovativeness (Evers, 2012).

Due to the specific field of research (i.e., education), some other confusion with respect to the name 'learning climate' occurs. Learning climate is often focused solely on the student learning climate (see for instance, Sebastian \& Allensworth, 2012). Others, however, see learning climate as both student learning, as well as the working (Hopson \& Lawson, 2011) and learning climate for teachers and staff (Evers, 2012). Learning climate has been operationalized in many ways. In our study we followed Van Woerkom (2003) who characterized learning climate by collective reflection, tolerance to different opinions, and learning from mistakes and other colleagues and teams as well as good practices from other organizations (Van Woerkom, 2003). The instrument of Van Woerkom (2003) was used in this research. Furthermore, we expected that ICT-infrastructure (incorporating a clear goal on ICT integration) and ICT competences of colleagues are affecting the learning climate.

\section{Dispositional variables and teachers' use of DLMs}

Within IMBP the dispositional variables predict the intention which, in turn, predicts actual behavior. Dispositional variables are mediators between the organizational variables and intentions. Previous research has confirmed their important role both in predicting human behavior in general (Fishbein \& Ajzen, 2010), as well as teachers' use of DLMs specifically (Kreijns et al., 2013)

Attitude, here defined as a general feeling of anti/sympathy considering the use of DLMs (Ajzen 1991), is highly related to teachers' ICT use (Tearle, 2003; Law \& Chow, 2008). It is suggested that when teachers develop negative attitudes to ICT usage in the classroom, it is 
very likely that indeed those teachers will not use ICT at all (Al-Zaidiyeen, Mei, \& Fook, 2010; Mahat, Jamsandekar, \& Nalavade, 2012).

Perceived norm refers to the experienced psychological pressure to perform certain behavior, here the use of DLMs. This pressure teachers experience comes from the social surrounding, being important others from the perspective of the teacher. Ajzen (1991) formulated the concept as "the perceived social pressure to perform or not to perform the behavior" (p. 188). $P B C$ (or self-efficay) in IMBP is operationalized as the degree of conviction that one can successfully use DLMs in class under certain inhibiting or stimulating conditions. PBC is considered to be an important variable when it comes to intention to perform a certain target behavior (Chen, 2011; Thoonen et al., 2011).

These dispositional variables have been operationalized in earlier research (Kreijns et al., 2013) and proven to be related to the intention to use DLMs (Van Acker, et al., 2013). Previous research showed that the intention to use DLMs predicted actual behavior (Vermeulen et al., 2014 ).

\section{Method}

Hypotheses. To answer the research question the following hypotheses were formulated (see Figure 1):

H1: TL-vision affects attitude, perceived norm, and PCB (path's 1a, 1b, and 1c)

H2: TL-individual consideration affects attitude, perceived norm, and PCB (path's 2a, 2b, and 2c)

H3: TL-intellectual stimulation affects attitude, perceived norm, and PCB (path's 3a, 3b, and $3 \mathrm{c})$ 
H4: TL-vison, -individual consideration, and -intellectual stimulation affect the quality of the ICT-infrastructure (path's $4 a, 4 b$, and 4c)

H5: Quality of the ICT-infrastructure affects learning climate (path 5)

H6: Quality of the ICT-infrastructure affects attitude, perceived norm, and PCB (path's 6a, $6 \mathrm{~b}$, and $6 \mathrm{c})$

H7: TL-vison, -individual consideration, and -intellectual stimulation affect learning climate (path's 7a, 7b, and 7c)

H8: $\quad$ Learning climate affects attitude, perceived norm, and PCB (path's 8a, 8b, and 8c)

H9: $\quad$ Attitude, perceived norm, and PCB affect intention (path's 9a, 9b, and 9c)

H10: Intention affects actual use of DLMs (path 10)

Data gathering. Between 2009 and 2014 a survey was administered to teachers in Dutch primary, secondary and vocational education at five points in time. The data gathering was part of the 'Wiki-Wijs' project (for more details see Vermeulen et al., 2014) and the TNONIPO panel of teachers was used to gather data over a period of four years by the same teachers. TL and ICT-infrastructure were measured in the December 2010 survey administration (T1, December 2010). Learning climate was measured in March 2012 (T2). Attitude, PBC, perceived norm, intention and the use of DLMs were measured in March 2013 (T3). The analyses were based on 544 teachers. Their characteristics are presented in Table 1 and compared with the characteristics of the general population of Dutch teachers as far as these were known. Men were slightly more represented in this study. 
Measures. The online survey consisted of scales based on existing and validated instruments. Some were adapted to the Dutch situation or on teachers' use of DLMs. Except for the variable 'actual use of DLMs', all variables were measured by at least three Likert scale items. Cronbach's alpha was calculated to check internal consistency (see Table 2).

\section{INSERT TABLE 2 ABOUT HERE}

Path analysis method. A structural equation modelling (SEM) was used to test the relative fit of the model (AMOS 20). Evaluating the model fit, $\chi^{2}$ statistic were used. With increasing model complexity and sample size, the $\chi^{2}$ statistic increases (Hu \& Bentler, 1999). Therefore, comparative fit index (CFI) (Hoyle, 1995; Marsh, Balla, and Hau,1996) and the root mean square error of approximation (RMSEA) (Browne, \& Cudeck, 1989) are reported.

\section{Results}

Direct relationships. Table 3 contains an overview of the bivariate correlations, the mean score, and standard deviation for each variable and the year the data was gathered. Strong direct relationships were found between the dimensions of TL themselves and with learning climate. All variables have a direct significant relationship with actual behavior. Only 
learning climate and the dispositional variables have a direct relationship with teachers' intention to use DLMs.

Path analysis. The model fit can be qualified as good $\left(\chi^{2}(544)=2413.67, p<.000\right.$;

$\mathrm{CFI}=.952 ; \mathrm{NFI}=.902 ; \mathrm{RMSEA}=.040)$. In Figure 2 only the significant relations and path parameters are drawn, including the three points in time of data gathering. The results supported the use of the IMBP for explaining the effect of factors at the school level on individual teacher behavior. The results also showed that the three dimensions were highly related within the concept of TL..

\section{INSERT FIGURE 2 ABOUT HERE}

From the three different hypotheses on TL affecting the dispositional variables attitude, perceived norm and PBC (i.e., H1, H2, and H3), hypothesis H1 (regarding TL-vision) was not confirmed. With regard to hypothesis H2 (regarding TL-individual consideration) only perceived norm was affected (-.27; path $2 \mathrm{c})$ but this turned out to be negative. With regard to hypothesis H3, TL-intellectual stimulation positively affected perceived norm (.34; path 3b) 
and $\mathrm{PCB}$ (.09; path 3c). Therefore $\mathrm{H} 1$ was rejected, whereas $\mathrm{H} 2$ and $\mathrm{H} 3$ were partially confirmed.

Furthermore, TL-vision was positively related to ICT-infrastructure (.32; path 4a) but not to learning climate (path 7a). TL-individual consideration was not related to the two variables on the school level (i.e., ICT-infrastructure, path 4b, and learning climate, path 7b). TL-intellectual stimulation was positively related to ICT-infrastructure (.21; path 4c) and learning climate (.45; path 7c). ICT-infrastructure also affected learning climate (.20; path 5). Therefore H5 was confirmed, whereas $\mathrm{H} 4$ and $\mathrm{H} 7$ were only partially confirmed.

Looking at the relationships of ICT-infrastructure and learning climate on the dispositional variables, only learning climate has a positive but small effect on attitude (.16; path 8a) and perceived norm (.15; path 8b). Therefore, $\mathrm{H} 6$ is rejected whereas $\mathrm{H} 8$ is partially confirmed.

The hypothesis H9 regarding the relationship from the dispositional variables on intention (the path's 9a, 9b, and 9c) was confirmed with respectively .51 (attitude), .22 (perceived norm) and .30 (PCB). Following this, hypothesis (H10) concerning intention affected teachers' use of DLMs was confirmed (.44; path 10). In other words, hypotheses H9 and $\mathrm{H} 10$ were fully confirmed.

\section{Discussion and conclusion}

In summary, no dominant path from TL to teachers' intention to use DLMs was found. The strongest path coefficients were found from TL intellectual stimulation to learning climate and to perceived norm. Although learning climate was related to attitude and perceived norm, these relationships were not strong. An important relationship was detected from TL-vision to ICT-infrastructure, but ICT-infrastructure only influences learning climate and was not related to any of the three dispositional variables. This finding is in contrast to our expectations based 
on Tondeur et al. (2008) and Tondeur et al. (2009) who found that goals and ICT policy highly affected teachers' integration of ICT.

Only TL-intellectual stimulation had a positive effect on the dispositional variables, in particular perceived norm. However, perceived norm had the weakest relationship to intention in comparison with the other dispositional variables. Attitude has the strongest relation with intention. This is completely in line with other previous research in which attitude has been suggested to be a key factor for teachers to integrate technology in education (Kim, et al., 2013). However, changing teachers' attitudes toward the intention of using DLMs is a complex endeavor in which leadership plays an important role. For instance in the collaboration processes which affect school culture or climate (Chen, 2008) and were culture was expected to affect teachers attitudes (Chen, 2011). Surprisingly, our results suggested that learning climate only has limited influence on attitude and that attitude is not affected by any of the other variables in our model (see Figure 2).

In contrast to our expectations, TL-individual consideration affected perceived norm negatively; the more TL shows individual consideration the less social pressure (perceived norm) was perceived by teachers. Negative relationships from TL-individual consideration with Dutch teacher behavior were found earlier and perhaps can be explained by the Dutch culture of too much attention for individual consideration (Thoonen et al. (2011).

Several conclusions can be drawn from these results. First, it was not solely one factor that could be viewed as the central cause of teachers' behavior; it was a mix of various factors that together influenced teachers' behavior to use DLMS.

Secondly, because of the longitudinal design we may conclude that TL influenced teachers' behavior through the mediating variables of ICT-infrastructure and learning climate and this has direct relationships with teachers' dispositional variables, which mediated the intention and the use of DLMs. 
Third, our findings that TL-vision and TL-intellectual stimulation had a significant positive impact may correspond to the findings of Leithwood and Jantzi (2006) who made a comment on the disappointing effects of TL in relation to school improvement. Based on their findings the use of DLMs should always focus on improving students' learning processes and outcomes; individual consideration should not distract from core organizational goals but should be supportive of achieving that goal.

This research has some limitations. First, self-reported questionnaires were used to assess actual behavior. Future research may use alternative techniques to gain data about the actual use and integration of DLMs in the classroom.

Second, only a small set of variables was used at the school organizational level. It can be expected that other variables, including team collaboration, professional learning communities, etc., could lead to a more promising path diagram with corresponding outcomes.

Third, although this study used longitudinal data measured at three points in time, real causality is difficult to establish because there are always unknown factors that can potentially influence the variables of interest.

Nevertheless, the current study reported here contributes to insights on the importance of TL as it has affected teachers' professional behavior in using DLMs over the years. Besides the detected significant direct influences of TL dimensions on the dispositional variables over the years, the longitudinal design revealed the effects of TL on the learning climate within the school. Learning climate, as a concept, is getting more attention over the last few years. Intellectual stimulation by school leaders affected the learning climate of the school strongly. Future research could seek for more insights on how the learning climate can influence teachers' behavior and what mediating variables at school level are important to enhance teachers' use of ICT in their educational practices. 
Finally, this research was built on existing empirical work testing the appropriateness of IMBP for teachers' use of DLMs. In the current article, IMBP was tested on data gathered at three points in time. IMBP proved to be suitable to map the different mediating and direct relationships on teachers' use of DLMs. As predicted by IMBP, direct relations from school level variables to the intention or use of DLMs were not significant, whereas indirect relations were all mediated by the three dispositional variables. When implementing new educational practices, teachers should therefore pay attention to these dispositional variables seeing as they play an important part in the intention to perform certain behavior. It should also be taken into consideration that it takes time to change teaching routines. 


\section{References}

Ajzen, I. (1991). The theory of planned behavior. Organizational Behavior and Human Decision Processes, 50, 179-211.

Al-Zaidiyeen, N. J., Mei, L. L., \& Fook, F. S. (2010). Teachers' attitudes and levels of technology use in classrooms: The case of Jordan Schools. International Education Studies, 3(2), 211-218.

Burns, J.M, (1978), Leadership, N.Y, Harper and Row

Browne, M. W., \& Cudeck, R. (1989). Single sample cross-validation indices for covariance structures. Multivariate Behavioral Research, 24, 445-455.

Carmeli, A., \& Schaubroeck, J. (2007). The influence of leaders' and other referents' normative expectations on individual involvement in creative work. The Leadership Quarterly, 18, 3548.

Chen, C. H. (2008). Why do teachers not practice what they believe regarding technology integration?.The Journal of Educational Research, 102(1), 65-75.

Chen, C. (2011). Factors Affecting High School Teachers' Knowledge-Sharing Behaviors. Social Behavior And Personality, 39(7), 993-1008

Deinert, A., Homan, A. C., Boer, D., Voelpel, S. C., \& Guterman, D. (2015).

Transformational leadership sub-dimensions and their link to leaders' personality and performance. The Leadership Quarterly, 26, 1095-1120.

Evers, A.T. (2012). Teachers' professional development at work and occupational outcomes: an organisational and task perspective. Unpublished doctoral dissertation. Heerlen: Open University.of the Netherlands.

Fishbein, M., \& Ajzen, I. (2010). Predicting and changing behavior: The reasoned action approach. New York: Psychology Press.

Geijsel, F. P., Sleegers, P. J. C., Stoel, R.D., \& Krüger, M. L. (2009). The effect of teacher psychological and school organizational and leadership factors on teachers' professional learning in Dutch schools. The Elementary School Journal, 109(4), 406-427. 
Hetland, H., Skogstad, A., Hetland, J., \& Mikkelsen, A. (2011). Leadership and Learning Climate in a Work Setting. European Psychologist, 16(3), 163-173.

Hopson, L., \& Lawson, H. (2011). Social workers leadership for positive school climates via data-informed planning and decision making. Children \& Schools, 33(2), 106.

Hoyle, R. H. (1995). Structural equation modelling: Concepts, issues, and applications. Thousand Oaks, CA: Sage.

Hu, L-T., \& Bentler, P.M. (1999). Cutoff criteria for fit indexes in covariance structure analysis: Conventional criteria versus new alternatives. Structural Equation Modeling, 6, $1-55$.

Kim, C., Kim, M. K., Lee, C., Spector, J. M., \& DeMeester, K. (2013). Teacher beliefs and technology integration. Teaching and Teacher Education, 29, 76-85.

Kreijns, K., Van Acker, F., Vermeulen, M., \& van Buuren, H. (2013). What stimulates teachers to integrate ICT in their pedagogical practices? The use of digital learning materials in education. Computers in Human Behavior, 29(1), 217-225.

Law, N., \& Chow, A. (2008). Teacher characteristics, contextual factors, and how these affect the pedagogical use of ICT. In: Law, N., Pelgrum, R. J., \& Plomp T. J. (Eds.), Pedagogy and ICT use in schools around the World. Findings from the IEA SITES 2006 study, Springer/Comparative Education Research Centre, The University of Hong Kong pp. 181-203.

Leithwood, K.A., \& Jantzi, D. (2006). Transformational school leadership for large scale reform: Effects on students, teachers, and their classroom practices. School Effectiveness and School Improvement, 17, 201-227.

Leithwood, K.A., Jantzi, D., \& Mascall, B. (2002). A framework for research on large scale reform. Journal of Educational Change, 3, 7-33. 
Mahat, S., Jamsandekar, P. P., \& Nalavade, K. M. (2012). A study of teachers attitudes towards ICT teaching process. International Journal of Information Technology and Knowledge Management, 6(1), 93-97.

Marsh, H. W., Balla, J. R., \& Hau, K. T. (1996). An evaluation of incremental fit indices: A clarification of mathematical and empirical properties. In G. A. Marcoulides \& R. E. Schumacker (Eds.), Advanced structural equation modeling: Issues and techniques (pp. 315-353). Mahwah, NJ: Erlbaum.

OECD (2014). TALIS 2013 Results: An international Perspective on Teaching and Learning. Paris: OECD Publishing.

Razzak, N. A. (2015). Challenges facing school leadership in promoting ICT integration in instruction in the public schools of Bahrain. Education and Information Technologies, 20(2), 303-318.

Scheuermann, F., \& Pedr, F. (Eds.) (2010). Assessing the effects of ICT in education: Indicators, criteria and benchmarks of international comparisons. Luxembourg: Joint Research Centre- European Commission.

Sebastian, J., \& Allensworth, E. (2012). The influence of principal leadership on classroom instruction and student learning. Educational Administration Quarterly, 48(4), 626-663.

Schneider, B. (2000). The psychological life of organizations. In N. M. Ashkanasy, C. P.M.Wilderom, \& M. F. Peterson (Eds.), Handbook of organizational culture \& climate (pp. xvii-xxi). Thousand Oaks, CA: Sage.

Sun, J., \& Leithwood, K. (2012) Transformational school leadership: Effects on student achievement. Leadership and Policy in Schools, 11, 418-451.

Tearle, P. (2003). ICT implementation: What makes the difference? British Journal of Educational Technology, 34(5), 567-583. 
Thoonen, E. J., Sleegers, P. C., Oort, F. J., Peetsma, T. D., \& Geijsel, F. P. (2011).

Motivation, organizational factors, and leadership practices. How to improve teaching practices: The role of teacher. Educational Administration Quarterly, 47(3), 496-536.

Thumin, F.J., \& Thumin, L.J. (2011), The measurement and interpretation of organizational climate. The Journal of Psychology, 145(2), 93-109

Tondeur, J., Valcke, M., \& van Braak, J. (2008). A multidimensional approach to determinants of computer use in primary education: Teacher and school characteristics. Journal of Computer Assisted Learning, 24, 494-506.

Tondeur, J., Devos, G., Van Houtte, M., van Braak, J., \& Valcke, M. (2009). Understanding structural and cultural school characteristics in relation to educational change: The case of ICT integration. Educational Studies, 35(2), 223-235.

Tobin, T., Muller, R., \& Turner, L. (2006). Organizational learning and climate as predictors of self-efficacy. Social Psychology Of Education, 9(3), 301-319.

Van Acker, F., Buuren, H., Kreijns, K., \& Vermeulen, M. (2013). Why teachers use digital learning materials: The role of self-efficacy, subjective norm and attitude. Education And Information Technologies, 18(3), 495-514.

Vanderlinde, R., Dexter, S., \& van Braak, J. (2012). School-based ICT policy plans in primary education: Elements, typologies and underlying processes. British Journal of Educational Technology, 43(3), 505-519.

Vanderlinde, R., van Braak, J., \& Dexter, S. (2012). ICT policy planning in a context of curriculum reform: Disentanglement of ICT policy domains and artifacts. Computers \& Education, 58, 1339-1350.

Van Woerkom, M., (2003) Critical reflection at work. Bridging individual and organizational learning. Unpublished doctoral dissertation. Enschede, the Netherlands: University of Twente. 
Vermeulen, M., Van Acker, F., Kreijns, K., \& van Buuren, H. (2014). Does transformational leadership encourage teacher's use of digital learning materials? Educational Management, Administration and Leadership (first online).

Voogt, J., Knezek, G., Cox, M., Knezek, D., \& ten Brummelhuis, A. (2013). Under which conditions does ICT have a positive effect on teaching and learning? A Call to Action. Journal of Computer Assisted Learning, 29(1), 4-14.

Vrasidas, C. (2015). The rhetoric of reform and teachers' use of ICT. British Journal of Educational Technology, 46(2), 370-380.

Wastiau, P., Blamire, R., Kearney, C., Quittre, V., Van de Gaer, E., \& Monseur, C. (2013). The Use of ICT in Education: a survey of schools in Europe. European Journal of Education: Research, Development And Policies, 48(1), 11-27.

Weng, C. H., \& Tang, Y. (2014). The relationship between technology leadership strategies and effectiveness of school administration: An empirical study. Computers \& Education, 76, 91107. 
Marjan Vermeulen,

Welten Institute, Open University Nederland, Valkenburgerweg 177, 6419AT Heerlen, email: marjan.vermeulen@ou.nl

Phone: +31 45-576 2546 Fax: 045 - 5762802 and

KPC Groep Kooikerweg 2 Den Bosch mail: m.vermeulen@kpcgroep.nl

Marjan Vermeulen works as a professor at Welten Institute of the Open University of the Netherlands and as senior consultant at a large educational consultancy organization the KPC Group 's-Hertogenbosch. Her expertise lies in supporting educational practice as well as educational research in the field of professional development of teachers, the school as a learning place for teachers, educational development and innovation.

Karel Kreijns,

Welten Institute, Open University Nederland, Valkenburgerweg 177, 6419AT Heerlen (+31 45 5762741), karel.kreijns@ou.nl

Karel Kreijns is associate professor at the Welten Institute, Open University the Netherlands. His current research interest are 1) the application of social presence theory on online learning networks, and 2) the application of self-determination theory and social cognitive behavior models on teachers' use of ICT (with a particular focus on digital learning materials/open educational resources) in their pedagogical practices.

Frederik Van Acker

Departement of Health and Social Care, Artesis Plantijn (AP) University College, Belgium F.vanacker@gmail.com

Frederik Van Acker has a MSc and PhD in psychology from the Vrije Universiteit Brussel and is Currently head of Remedial Teaching of the Department Health and Social Care at the 
Artesis Plantijn University College in Antwerpen, Belgium. His main research interests are research methodology and the use of ICT in education.

\section{Hans Van Buuren,}

Faculteit Psychologie, Open University Nederland, Valkenburgerweg 177, 6419AT Heerlen hans.vanBuuren@ou.nl

Hans van Buuren is associate professor at the School of Psychology Open University the Netherlands. His expertise lies in teaching research methodology and especially statistics and writing study books about it. His main research interests are 1) investigating the impact of new teaching tools in statistics education, and 2) the use and of ICT and OER in Dutch education. 
Table 1. Characteristics of the teachers: gender, age and type of school $(N L=$ population characteristics in the Netherlands|)

\begin{tabular}{l|cccc}
\hline & Primary (NL) & Secondary (NL) & Vocational (NL) & Total (NL) \\
\hline Men \% & $19 \%(15 \%)$ & $55 \%(50 \%)$ & $66 \%(49 \%)$ & $39 \%(32 \%)$ \\
Age $(M)$ & $41(43)$ & $44(45)$ & $47(48)$ & $43(44)$ \\
Years of & 16 & 17 & 16 & 16 (not known) \\
educational experience $(M)$ & & & & \\
\hline & 241 & 203 & 102 & \\
Total & $44,7 \%$ & $27,5 \%$ & & \\
\hline
\end{tabular}


Table 2. Overview of the scales, the source of the scale, answer categories and items.

\begin{tabular}{|c|c|c|}
\hline Scale and source & Answer categories & Items \\
\hline $\begin{array}{l}\text { Intention } \\
\text { Kreijns et al., (2013) }\end{array}$ & $\begin{array}{l}1=\text { 'absolutely } \\
\text { unlikely' ... } \\
7=\text { 'extremely likely' }\end{array}$ & $\begin{array}{l}\text { Please indicate to what extent the following statements apply to you: } \\
\text { a. I plan to use digital learning materials during class regularly. }{ }^{1} \\
\text { b. I intend to use digital learning materials during class regularly. } \\
\text { c. I think I should use digital learning materials during class regularly. } \\
\text { d. I expect to use digital learning materials during class regularly. }\end{array}$ \\
\hline $\begin{array}{l}\text { PBC } \\
\text { Geijsel, et al. (2009) }\end{array}$ & $\begin{array}{l}1=\text { ='completely not } \\
\text { true' ... } \\
7=\text { 'completely true' }\end{array}$ & $\begin{array}{l}\text { a. I am able to regular use DLMs effectively in my classes. } \\
\text { b. I am satisfied with the way I regularly use my DLMs. } \\
\text { c. I feel successful in the deployment of DLMs regularly }{ }^{1} \text { in my classes. } \\
\text { d. I am confident enough in the regular use of DLMs in my classes. }\end{array}$ \\
\hline $\begin{array}{l}\text { Attitude } \\
\text { Based on Kreijns, et } \\
\text { al., (2013) }\end{array}$ & by bipolar scales & $\begin{array}{l}\text { For me, to use digital learning materials during class regularly }{ }^{I} \text { is } \ldots \\
\text { a. } 1=\text { 'necessary' }-7=\text { 'not necessary' } \\
\text { b. } 1=\text { 'desirable' }-7=\text { 'un desirable' } \\
\text { c. } 1=\text { 'wrong' }-7=\text { 'good' } \\
\text { d. } 1=\text { 'fantastic' }-7=\text { 'horrible' } \\
\text { e. } 1=\text { 'constructive' }-7=\text { 'destructive' } \\
\text { f. } 1=\text { 'embracing' }-7=\text { 'rejecting' } \\
\text { g. } 1=\text { 'disappointing' }-7=\text { 'above expectations' } \\
\text { h. } 1=\text { 'nonsense' }-7=\text { 'useful' }\end{array}$ \\
\hline $\begin{array}{l}\text { Perceived norm } \\
\text { Self-constructed }\end{array}$ & $\begin{array}{l}1=\text { 'not applicable' } \ldots \\
7=\text { 'fully applicable' }\end{array}$ & $\begin{array}{l}\text { a. I certainly get the impression that I should use DLMs in my classes regularly. } \\
\text { b. People think I should use DLMs in my classes regularly. } \\
\text { c. It is urged strongly that I should use DLMs in my classes regularly. } \\
\text { d. I cannot refuse to use DLMS in my classes regularly. }\end{array}$ \\
\hline $\begin{array}{l}\text { Learning } \\
\text { climate } \\
\text { Van Woerkom, } \\
(2003)\end{array}$ & $\begin{array}{l}1=\text { 'not applicable' } . . \\
7=\text { 'fully applicable' }\end{array}$ & $\begin{array}{l}\text { a. there is time allocated for working together on our professionalism. } \\
\text { b. There is are many contacts between different teams from my school. } \\
\text { c. We exchanged experiences with schools that have similar problems. } \\
\text { d. Employees who disagree have to be respected here. } \\
\text { e. It is time allocated for making plans for improvement. } \\
\text { f. In my school we reflect on what has gone good and not gone well. } \\
\text { g. In my school we look for causes of success and failure. } \\
\text { h. You can learn from mistakes, is morality in my school. } \\
\text { i. My school is careful with complaints of 'customers' (students, parents and external). } \\
\text { j. Employees jointly reflect on what needs to be unlearned. } \\
\text { k. Employees are involved in important innovations in my school. }\end{array}$ \\
\hline $\begin{array}{l}\text { ICT infrastructure } \\
\text { Tondeur et al. } \\
\text { (2008). }\end{array}$ & $\begin{array}{l}1=\text { 'not applicable' } \ldots \\
7=\text { 'fully applicable' }\end{array}$ & $\begin{array}{l}\text { a. There is a good ICT-infrastructure (e.g., available PC`s, Internet connections) } \\
\text { b. There is a good range of educational software: programs and digital learning. } \\
\text { c. Most teachers have sufficient knowledge and skills to use DLMs } \\
\text { d. The school has a clear vision on the use of DLMs. } \\
\text { e. There is an ICT policy that is actually performed. }\end{array}$ \\
\hline $\begin{array}{l}\text { Trans-formational } \\
\text { leadership: vision } \\
\text { Geijsel, et al. (2009) }\end{array}$ & $\begin{array}{l}1=\text { 'not applicable' } \ldots \\
7=\text { 'fully applicable' }\end{array}$ & $\begin{array}{l}\text { The leadership of my school } \\
\text { a. uses all possible occasions to stipulate the vision of the school to the team, students and others. } \\
\text { b. refers explicitly to school goals during decision-making processes } \\
\text { c. clarifies for the team the relationship between the vision of school and various initiatives taken from } \\
\text { the board, partnerships or national government } \\
\text { d. describes in a clear manner, based on the schools' vision the current problems } \\
\text { e. outlines at meetings what the consequences are of the schools' vision for the current ins and outs. }\end{array}$ \\
\hline $\begin{array}{l}\text { Trans-formational } \\
\text { leadership: individual } \\
\text { consideration } \\
\text { Geijsel, et al. (2009) }\end{array}$ & $\begin{array}{l}1=\text { 'not applicable' } \ldots \\
7=\text { 'fully applicable' }\end{array}$ & $\begin{array}{l}\text { The leadership of my school } \\
\text { a. takes the views of individual teachers seriously } \\
\text { b. shows appreciation when a teacher take the initiative for improving education. } \\
\text { c. listens carefully to the ideas of team members. } \\
\text { d. helps teachers to express their emotions } \\
\text { e. has an eye and ear for problems experienced by teachers when introducing innovations }\end{array}$ \\
\hline $\begin{array}{l}\text { Trans-formational } \\
\text { leadership: } \\
\text { intellectual stimulus } \\
\text { Geijsel, et al. (2009) }\end{array}$ & $\begin{array}{l}1=\text { 'not applicable' } . . \\
7=\text { 'fully applicable' }\end{array}$ & $\begin{array}{l}\text { The leadership of my school } \\
\text { a. helps teachers to express and clarify their personal ideas about teaching } \\
\text { b. encourages teachers to try out new things in line with their interests } \\
\text { c. helps teachers to reflect on new experiences that they acquire as a teacher } \\
\text { d. encourages teachers to think about how to improve our institution / department } \\
\text { e. encourages the search for and discussing of new information and ideas relevant to the development of } \\
\text { the institution / program } \\
\text { f. involves individual teachers in an ongoing debate about their personal professional goals } \\
\text { g. encourages teachers to experiment with new teaching methods } \\
\text { h. creates ample opportunities for teachers to develop professionally }\end{array}$ \\
\hline
\end{tabular}

'regularly is defined as 'a few times a week during the school year' 
Table 3. Year of data gathering, number if items, means (M), standard deviation (SD)

Cronbachs' Alpha (cursive) and correlations $(n=544)$

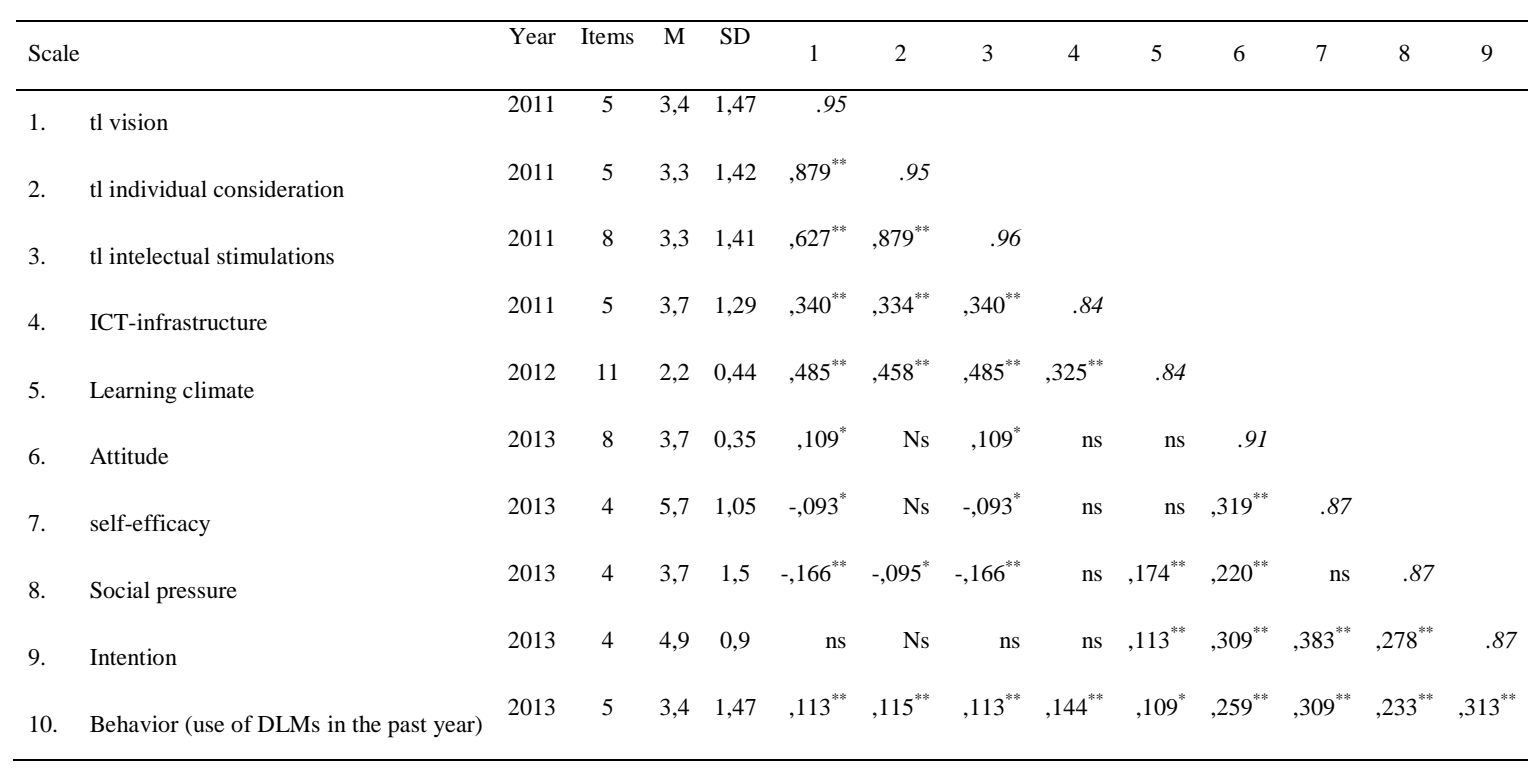




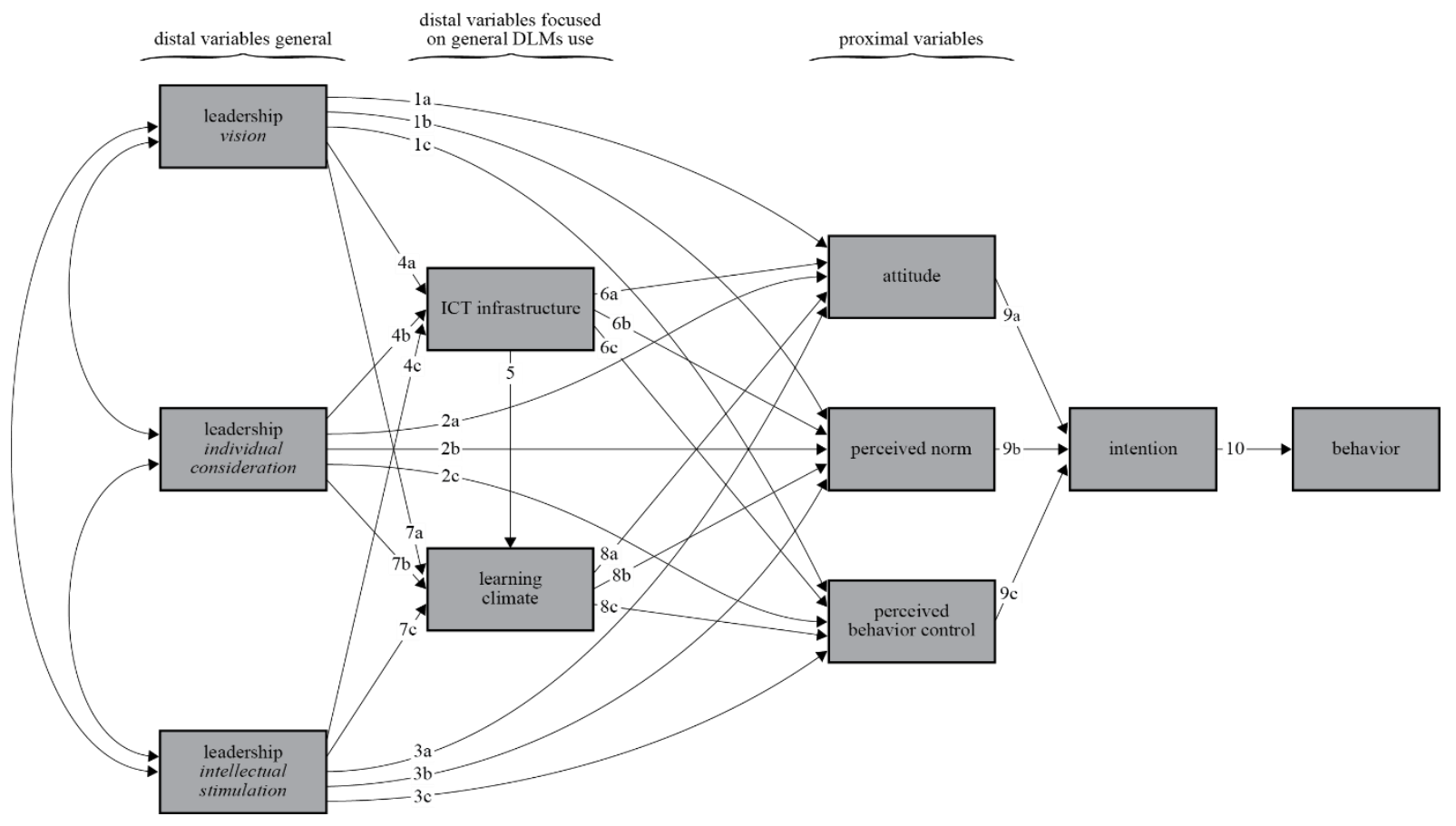

Figure 1: Conceptual model for the influence of leadership on teachers' use of DLMs. 


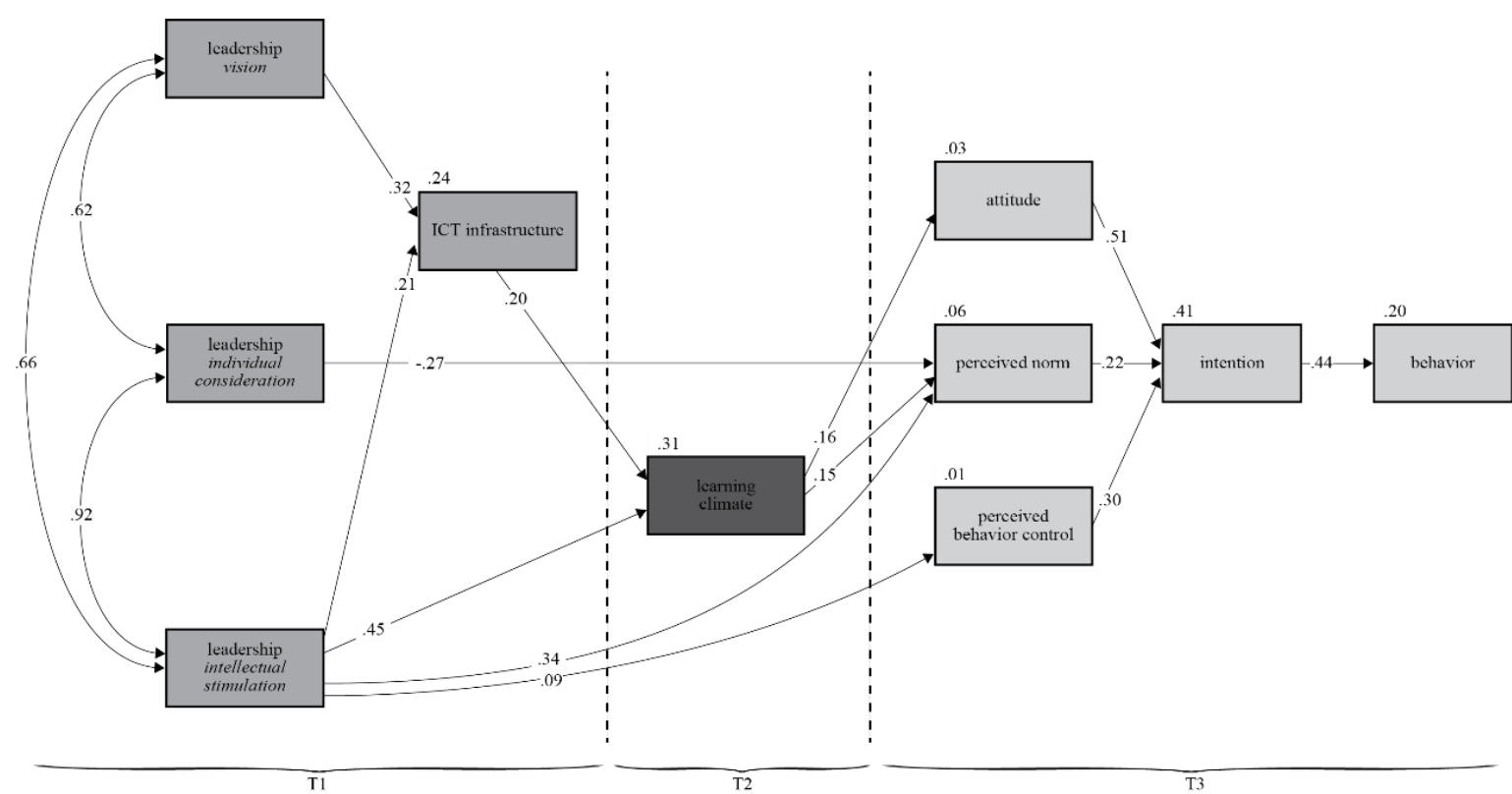

Figure 2. The influence of leadership on teachers' use of DLMs, measured on three points in time $(2011,2012,2013)$ in time $(\mathrm{n}=544)$. 